\title{
A Functional Analysis of Future Tense Variations in Persian Language
}

\author{
Mostafa Rahimirad \\ Department of Foreign Languages, Allameh Tabatabai `e University, Tehran, Iran \\ Email address: \\ mostafa60rahimi@gmail.com

\section{To cite this article:} \\ Mostafa Rahimi Rad. A Functional Analysis of Future Tense Variations in Persian Language. Communication and Linguistics Studies. \\ Vol. 5, No. 2, 2019, pp. 30-44. doi: 10.11648/j.cls.20190502.11
}

Received: April 21, 2019; Accepted: June 3, 2019; Published: June 18, 2019

\begin{abstract}
Temporal references have been the subject of many studies around the world. Futurity is specially an elusive concept really difficult to perceive and describe. The present study tries to launch an investigation regarding the variability of future tense in Farsi. 130 sentences extracted from 8 interviews have been explored along with age, gender, presence or absence of temporal adverbial and animacy of the subject. 5 possible variabilities for expressing futurity are considered in the present study. Future time is especially difficult to perceive and in fact it might not occur. This forces us when it comes to the modality in which statements about the future may be interpreted. Not only do we just talk about those future events which are planned, but also that is the only (natural) modality that we can ascribe to those events. We suggest that the notion of future tense or futurity marking is a second class function, and the means available to futurity marking are typically borrowed from other constructions in the language. However, before a further discussion of the circumstances giving rise to the idea, as well as some facts that seem to follow from this constraint on modality, we would like to give a brief sketch of some ways that futurity is expressed in different languages. This paper studies that the Persian is not only conditioned by linguistic factors, it also most likely follows of development similar to English.
\end{abstract}

Keywords: Paraphrastic Constructions, Tense Less Future, Age Variations, Future Variations, Persian Future Tense, Variationist Analysis

\section{Introduction}

Directly perceiving Time is impossible. The effects of its passage on the world are obvious, but there is no particular "time-sensing" organ analogous to human light-sensing organs (our eyes). Thus, in some sense our perception of time is similar to our perception of motion (as we also lack a particular "motion-sensing" organ); they are secondary perceptual and cognitive functions.

Many indo-European languages have paraphrastic constructions mark futurity. In some languages, the "Future" auxiliary can also stand on its own as a main verb of a clause; yet, in other languages, it cannot. English actually has both types of future auxiliary. Typically, English uses "will" plus a bare verb to indicate future tense. In modern English, "will" cannot stand on its own as a main verb. However, English also uses the progressive form of go (going) plus an infinitival verb to mark future (often shortened gonna V.). Go, of course, can stand on its own. German uses warden ("become") plus an infinitival verb to mark futrue1. Unlike English "will" (ye similar to English go), warden can also be used by itself as a main verb with the meaning "become"; Im fruhling warden die baume grun "In spring the trees become green." However, despite having this construction at their disposal, German speakers tend to use a present tense verb with a time adverbial to express futurity. As Comrie notes:

"The languages [German and Finnish] "do" also have specific constructions with exclusively future time reference, e.g. German 'ich werde gehen', ... but such constructions are normally only used where there would otherwise be danger of misunderstanding" [1]. Next, we look at French language. In French actually, there is a future tense affix on the verb. Still, French does have a parphrastic which uses the verb aller ("go") plus an infinitival verb. There is also the present tense with time adverbial construction, more frequently than in English and more on a par with German [2].

Finally, we turn to serbo-croatian. Future tense is typically expressed by using a clitic formed from the verb hetti 
"want". Its behavior is interesting, because of the requirement in serbo-croation that clitics immediately follow the first word in the sentence. While this is not directly relevant to the issue of tense, it is important to note that marking for future tense follows the idiosyncrasies of the individual language, and not any more universal principle ruling the grammaticalization of tense. Serbo-croatian also has paraphrastic with the auxiliary biti that can express future, as well as the use of an explicit time adverbial with present tense. It is in non-Indo-European languages that one finds many representatives of what are termed "tense less" languages [3]. There is no inflection on the verb to mark tense. Temporal reference must come from somewhere else. In Burmese, for example, there is a sentence final irrealis particle me. This marker may be used to indicate future, but in certain circumstances can also be used to simply mark a sort of "possible world" modality. In these instances, it is used in conjunction with its counterpart realis particle (which is interpreted as indicating present or past tense). In fact, Comrie suggests that futurity is not the primary function of this particle:

"Rather, future time reference is just one of the interpretations possible for the irrealis, and there is no reason to assume that it is significantly more basic than any of the other interpretations of this form." [4]

Vietnamese is another language where the verb shows no inflection for tense. To indicate futurity, Vietnamese speakers typically use a parahrastic construction with the auxiliary s. that is similar in meaning to modern English "will". In addition, and in accordance with an emerging pattern, adverbials can also be used to indicate future time.

Sociolinguists tend to focus on spontaneous speech used in ordinary conversational situations. The variationist approach to sociolinguistics involves open-ended procedures to obtain representative and comparable data, which contrasts with principles of control and predictability in other experimentalevaluative approaches [5]. The variationist method relies on quantitative analysis to validate interpretations of the data. The purpose of the quantitative method is to highlight the sociocultural meaning of linguistic variation and the nature of the relationships among the linguistic aspects in probabilistic terms. The use of quantitative analysis is not a minor methodological detail. It provides a more accurate understanding of the usage and the frequency of the forms within the community as well as a way of detecting linguistic change. The frequency of forms and speakers' preferences give a more realistic overview of the usage of linguistic structures. More importantly, statistical tools allow us to pinpoint the social and linguistic conditioning as well as the tendencies and regularities within the linguistic system. Being a more objective and accurate basis of analysis than intuitions and judgments of value, the quantitative method is a powerful and efficient tool. Animacy is an overlooked feature among the set of $\Phi$-features. Person, number, and gender have drawn more attention than animacy in the literature. This feature has recently been the subject of some discussion. For instance Ormazabal \& Romero propose that
Bonet's PCC constraint1 is in fact triggered by the presence of animacy in object agreement. Moreover, animacy in Russian has been of particular interest in the literature, since it is reflected in the accusative case form of certain nouns and in the agreement of adjectives [6].

\section{Review of Related Literature}

Researches on temporal references generally and future tense specifically have been carried out by many researchers in the past. Some researchers have attempted to compare the same tense or mood in two or more related languages. Some others have given descriptive accounts of particular languages without comparing or contrasting them with any other languages. In a study by Olga Mis oska Tomic, the syntax of the Bakjan Slavic future tense was investigated. The structure of the Balkan Slavic future tenses, with a particular reference to the future tenses with modal clitics and finite verbs was discussed in the study. It is shown that all the Balkan Slavic future tenses have developed from restructuring configurations in which subjunctive constructions appear in complement positions of from of the Old Slavic verb xote ti will/want'[7].

The development has gone through three stages, though not all Balkan Slavic languages have gone through all of them. In the first stage, represented in contemporary SerboCroatian, we have finite modal clitics plus infinitives or subjunctive constructions. In the second stage, which is to some extent represented in the south-eastern Serbian dialects, non-finite modal clitics are followed by subjunctive constructions. In the third stage, represented in Macedonian and Bulgarian, non-finite modal clitics are followed by finite verbs. In contemporary Serbo-Croatian, the future tense is constructed by finite modal clitics plus infinitive or subjunctive constructions. The Serbo-Croatian future tense with subjunctive constructions is a mono-clausal raising configuration with a finite auxiliary and a finite lexical verb. Like the Macedonian and Bulgarian future tenses, it has evolved from a restructuring configuration with two finite lexical verbs, though the evolution of the Macedonian and Bulgarian future tenses has passed through three stages. In the first stage, the Macedonian and Bulgarian future tenses had a structure such as the one in the Serbo-Croatian future tense; in the second stage, they had another intermediate structure-the one witnessed in the contemporary southeastern Serbian dialects, in which a non-finite modal clitic is followed by a subjunctive construction; in the third stage, the non-finite modal clitics came to be followed by finite verbs. The change from finite to non-finite modal clitics relates to the loss of the subjunctive mood complementizer: when the $\mathrm{j}$ features of the modal clitics disappeared and T/AgrSP reappeared to the left of the lexical verb, the subjunctive mood complementizer became superfluous. [8]

In another research, jo-wing lin explored the selective restrictions of tenses and temporal reference of Chinese bare sentences. He discussed temporal reference of Chinese bare sentences without any time adverb or tense-like marker. They 
argued that temporal reference of such sentences can be resolved by selective restrictions of two empty tenses, i.e., covert present tense and covert past tense. They showed that while covert present tense must select a homogeneous situation as its complement, covert past tense must select heterogeneous situation as its complements. They also argued that covert tense must be distinguished from empty tenses that agree with time adverbs, because the latter do not have selective restrictions.

The future tense of Spanish has also been investigated by some researchers. Christopher G. Lyons contends that it has been suggested that languages show a tendency to alternate between synthetic and analytic construction, synthetic forms being replaced by analytic ones, and these then resynthesizing. The first stage in this sequence is exemplified by many developments in early romance, and it is not discussed here. The second stage appears in the resynthesization of the early romance analytic future tense from in Hispano-Romance (as well as in other Romance languages). This process can be related to many regular changes in early Spanish, but part of it, the reduction of the auxiliary habeo, is not well understood, and is examined in detail. All the factors involved in the resynthesization of the analytic future appear to be phonological, and the development seems to be the result of changes specific to Spanish; it cannot therefore be attributed to a universal trend, though it may be that analytic constructions exhibiting the word order found in this one are particularly susceptible to synthesization through sound change.

English tense including future tense has also intrigued many researchers. Anoop sarker in an article called"the conflict between future tense and modality: the case of will in English"asserts that there have been different views in the literature on what the semantics of "will" should constitute. Some consider "will" to be homonymous between a modal and a periphrastic future tense, while some deny that it is a future tense, indicating that its futurity is derived from its modality. In his paper, sarker reviews the evidence for both views and draws a conclusion based on an empirical comparison. [9]

Any consideration of future forms in English will at once come across the vexed question of whether English possesses such a thing as a "future tense". It is questionable whether English possesses such a structure; as comrie points out, "most European languages have a clear grammatical distinction between past and non-past ... but either no grammatical distinction or a much less clear grammatical distinction between future and non-future. "This may well be because "expressions of future time derive diachronically from modal expressions, e.g. of desiderativity such as the English will" [10].

Hornstein states confidently that "English has a future tense and will is the modal that marks it", going on to claim that "will as future tense acts quite differently from modal will" [10]. However, there are good reasons to doubt this claim; as Lyons points out, "futurity is never a purely temporal concept; it necessarily includes an element of prediction on some related notions." It is worth noting that in predictive sentences can be replaced by other epistemic modals, resulting in a loss of certainty but not of futurity.

If we accept for the sake of argument that will, whatever time it refers to, is a modal operator, the question remains as to what it conveys. Palmer lists no less than seven functions of will (of which only one is epistemic), while from the point of view of speech act theory (see, for example, Austin, Coulthard, will can be directive (you will do it / will you do it?), commissive (I'll do it) or deductive (He'll do it). The process for determining the particular meaning of will is dealt with in some detail by Ney, who also provides a useful componential analysis of the various modals. [11]

The futures referred to are the simple present and present progressive "tenses"; there are also good reasons for grouping the structure be going to with the futurities. The notable feature of these is that the form in each case uses the present either in the main verb or with the auxiliary be, so it is perhaps not unreasonable to assume, with Binnick that this is due to the present's having "current relevance". However, an analysis of futurates should not restrict itself solely to the present, since, as smith points out, "the futurate requires some kind of plan, schedule, control, or pattern of events," and many if not most of these involve some reference to past events. This simple present or "tenseless future" is usually associated with fixed schedules, as in the train leaves at fivethirty. However, this does not seem to be a prerequisite for the use of this form, as shown be Dowty's example:

"Oh, number five wins the competition. His performance was unquestionably better than the others".

The crucial feature of this futurate seems to be that "the outcome of the matter has already been decided" [11]. we might add here "not by the subject", since the only cases where actions originally initiated by the subject take this form are sentences such as I leave tomorrow where although the subject may have initiated a chain of events (by booking a place on a tour, for example) it is now seen as outside their control. This parallels Wecker's view that present progressive futurate indicates a human agent; while in the simple present the agent is an event.

It is sometimes suggested that the simple present futurate implies certainty on the part of the speakers. While this may normally be the case, it is not necessarily so Dowty,. On some rail networks, the statement the train leaves at fivethirty may be more a matter of faith than certainty; the train will leave at five-thirty may actually inspire more confidence. Without delving into "possible worlds" and international logic, the best explanation seems to be that this form carries a sense of in the normal course of events or ceteris paribus. [12]

The use of the present progressive seems bound to general consideration of progressive aspect. Perhaps the most elegant way of describing this is found in Hofmann, following Reichenbach. If an event $\mathrm{E}$ has a beginning $\mathrm{B}$ and a finish $\mathrm{F}$, then a predicate using the progressive would normally imply: $\mathrm{B}<\mathrm{R}$ and $\mathrm{F}>\mathrm{R}$, where $\mathrm{R}$ is the time referred to, and the symbols $<$ and $>$ mean "before" and "after" respectively. If $\mathrm{R}=$ 
$\mathrm{S}$ (the time of speaking), then we use the present progressive (for a more formal semantic view of the progressive, and problems arising from this type of analysis, see Dowty, Saurer and Ogihara.[13] This explains the choice of present progressive for actions which are actually taking place at the time of speaking (I am writing an essay now) but leaves the question of why we would use this form for actions in the future. Hofmann explains this by saying that an action in the past sets in motion an event in the future, bringing forward the beginning of that event. Dowty although woring from a different analysis, takes a similar view of "a psychological tendency of humans to extend the temporal 'duration' of an accomplishment ... backward in time to include the preparations for the accomplishment proper."[14]

In Farsi we can also find some works on tenses. Ina study done by Ahmad Reza Lotfi tense, IP, and parametric variations are investigated. This study represents an attempt

$\begin{array}{cl}\text { Exp1: } & \begin{array}{l}\text { Che mikuni? } \\ \text { Shahnameh mikhanam }\end{array} \\ \text { Exp2: } & \begin{array}{l}\text { Farda be park miayee? } \\ \text { Shayad biayam }\end{array} \\ \text { Exp3: } & \begin{array}{l}\text { Hafteye dige be Shiraz miravi? } \\ \text { Ghasd daram beram }\end{array} \\ \text { Exp4: } & \begin{array}{l}\text { Dar moddate taatilat kar mikoni? } \\ \text { Khodam ra baraye konkur amadeh khaham kard. } \\ \text { (I will prepare myself for university entrance exam) }\end{array} \\ \text { Exp5: } & \text { Kharid rafti? } \\ & \text { Raftam }\end{array}$

to explore tense in terms of some temporal features [+/-past, +/-present, +/-future] in relation to TS (temporal standpoint), i.e. where the speaker stands on the time continuum towards which the speaker's / listener's. [15]

\section{Method}

\subsection{Future Tense in Farsi}

The expression of future temporal reference in Farsi is one of the controversial issues of the grammar of Farsi. The speakers of Farsi use various structures and different tense to talk about a future activity. A speaker may use present tense to talk about his future activity. Surprisingly, the speakers of Farsi sometimes use past tense to talk about future. Now look at some variants of the future temporal reference.

What are you doing?

I'm reading Shahnameh.

Do you come to park tomorrow?

I want to go.

Do you go to Shiraz next week?

I want to go.

What are you doing during the vacation?

Did you go shopping?

I did.

Most of these tenses which were used to indicate a future activity are also used to talk about present. Future verb in Farsi defined to be made by the verb KHASTAN. The future tense conjugation of the verb is shown in Table 1.

Table 1. The future conjugation of raftan

\begin{tabular}{lll}
\hline Persian & Farsi future & English future \\
\hline $1^{\text {st }}$ person (sing) & Kaham raft & I will go \\
$2^{\text {nd }}$ person (sing) & Kahi raft & You will go \\
$3^{\text {rd }}$ person (sing) & Khahad raft & He/ she will go \\
$1^{\text {st }}$ person $(\mathrm{pl})$ & Kahim raft & We will go \\
$2^{\text {nd }}$ person $(\mathrm{pl})$ & Khahid raft & You will go \\
$3^{\text {rd }}$ person $(\mathrm{pl})$ & Khahand raft & They will go \\
\hline
\end{tabular}

The above mentioned future verb is used to talk about an activity whose occurrence is definite in the future. In the examples the person is determinedly going to prepare himself for the entrance exam. In the present study, the researchers are going to focus on the frequency of occurrences of this future verb along with other varsiants of future temporal references. It seems that in the standard dialect of Farsi speakers in Iran- the study assumes to be the dialect of Tehrani speakers of Farsithere is not so much references to the future verb to talk about future activities or intentions. So, it is founded as worthwhile to launch an investigation in this regard. Attention is directed.

\subsection{Data Collection}

For the purpose of this study we limited the context of our study to Tehrani speakers to Farsi, Eight people were interviewed. Special attempts were made to conduct informal, naturalistic conversations with interviewers. Participants were selected based on specific criteria. They were chosen according to their age and gender. We wanted to observe the variation of the use of future temporal reference along with both different age and sex groups. Four female speakers and four male speakers were interviewed. Regarding their age we divided our participants in two groups above 40 (old) and below 40 (young). Each of these groups consisted of two males and two females. Interviews were all conducted for the time limitation about 1 hour and then the recordings were transcribed and the sentences which were references to future selected. 130 sentences were extracted and worked on.

As it was mentioned before the interviewers tried to direct the interviews in ways to make our participants talk about future. Some points regarding the interviews are worth considering. A profound tendency was found towards analyzing the past or present status when the subjects were asked to talk about future. As an example one of the basic questions that we asked our subjects was that of the predication of a football game. Almost all of our subjects 
tried to interpret the previous games and present conditions of the players and at the end make a promising or disappointing prediction. For about for or five minutes they talked about football, not more than two sentences could be extracted from each subject related to our interest.

\section{Discussion}

\subsection{Factor Groups}

Variability in reference to future time is hypothesized to be influenced by several factors. Most of these variability's rely on the speakers' intentions or attitudes towards the realization of future activity. Each researcher can consider several and different factors which he supposes to have effects on the selection of one of those variabilities. We also coded some factors and tried to explore the variability of our dependent variable on those factors. Factors are listed:

1. Gender $(\mathrm{m}=$ male, $\mathrm{f}=$ female $)$.

2. Age $(\mathrm{O}=$ old $>40)$. $\mathrm{Y}=$ young $[<40])$.

3. Animacy of subjects ( $\mathrm{a}=$ animate, $\mathrm{u}=$ inanimate $)$.

4. Temporal adverbial ( $+=$ with adverb, $-=$ without adverb).

5. The interviewees $(1,2,3,4,5,6,7,8$ stand for eight participants).

6. The interviewers $(\mathrm{c}=$ the first interviewer, $\mathrm{d}=$ the second interviewer).
Our first claim is to test whether these claims hold up against actual usage. Pondering, about variabilities in the use of future temporal reference in Farsi, as it was exemplified at the beginning, we considered five variabilities in the use regarding the first five examples we mentioned in the article:

$1: \mathrm{W}=(\exp 4)$ Khaham Raft.

$2: \mathrm{S}=(\exp 2)$ present tense for indicating futurity.

$3: b=(\exp 3)$ shows an intention or a decision for the future, not a definite decision.

4: $\mathrm{e}=(\exp 2)$ the use of words like bayad $=$ should or shayad $=$ may to show intention.

$5: \mathrm{t}=$ the use of present perfect for future.

Exp: Nasle baad fekrha fagh kadeh-and (next generation tinking has changed).

The future verb is defined, as it was explained before, as number one, with verb khastan. We hypothesized that in standard dialect of Farsi there is not so many resources to this variability to talk about future. Our objective is to test how much our hypotheses hold true.

\subsection{Result and Interpretation}

We are now going to discuss and interpret the findings of the study based on thse factors we considered to have effects on vaiabilities of future. Table 2 categorizes our interviews based on their gender and shows the number and percentage of each variability that subjects used.

Table 2. Interviews based on their female gender.

\begin{tabular}{|c|c|c|c|c|c|c|c|c|c|}
\hline & group1 & group2 & group3 & group4 & group5 & group6 & group7 & group8 & sum group \\
\hline $\mathrm{s}$ & 13 & 0 & 4 & 0 & 0 & 12 & 6 & 0 & 35 \\
\hline e & 2 & 0 & 0 & 0 & 0 & 2 & 5 & 0 & 9 \\
\hline b & 1 & 0 & 8 & 0 & 0 & 1 & 1 & 0 & 11 \\
\hline w & 0 & 0 & 1 & 0 & 0 & 0 & 4 & 0 & 5 \\
\hline $\mathrm{t}$ & 0 & 0 & 0 & 0 & 0 & 0 & 0 & 0 & 0 \\
\hline sum & 16 & 0 & 13 & 0 & 0 & 15 & 16 & 0 & 60 \\
\hline
\end{tabular}

Table 3. Percentage of female.

\begin{tabular}{|c|c|c|c|c|c|c|c|c|c|}
\hline & group1 & group2 & group3 & group4 & group5 & group6 & group7 & group8 & sum group \\
\hline $\mathrm{s}$ & 81.25 & 0 & 30.77 & 0 & 0 & 80 & 37.5 & 0 & 58.33333333 \\
\hline e & 12.5 & 0 & 0 & 0 & 0 & 13.33 & 31.25 & 0 & 15 \\
\hline $\mathrm{b}$ & 6.25 & 0 & 61.54 & 0 & 0 & 6.667 & 6.25 & 0 & 18.33333333 \\
\hline w & 0 & 0 & 7.692 & 0 & 0 & 0 & 25 & 0 & 8.333333333 \\
\hline $\mathrm{t}$ & 0 & 0 & 0 & 0 & 0 & 0 & 0 & 0 & 0 \\
\hline sum & 100 & 0 & 100 & 0 & 0 & 100 & 100 & 0 & 100 \\
\hline
\end{tabular}

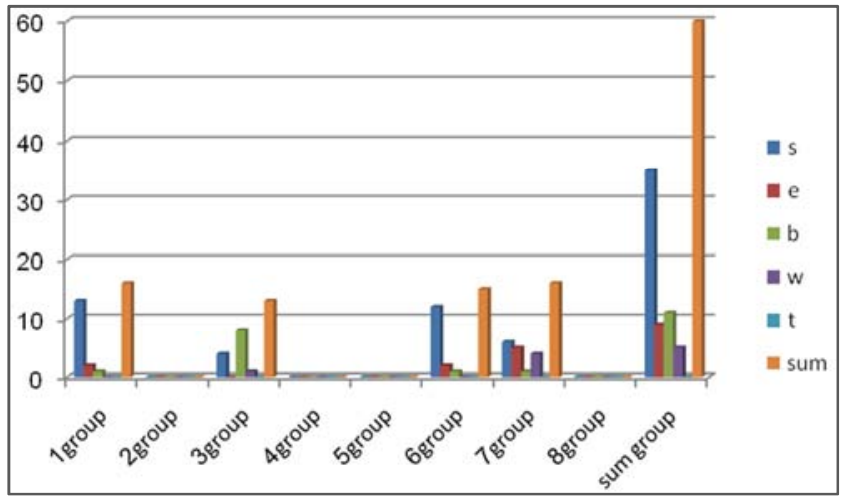

Figure 1. Percentage of female based on Interview.

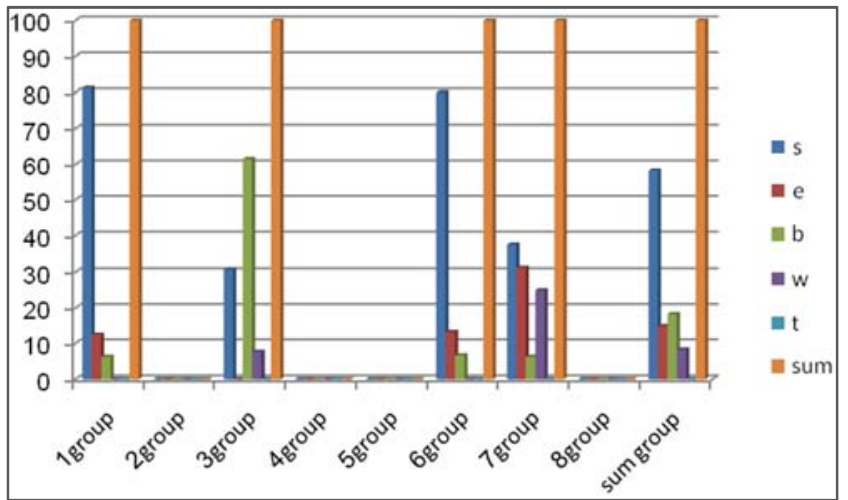

Figure 2. Percentage of female based on Interview. 
Table 4. Interviews based on their male gender.

\begin{tabular}{llllllllll}
\hline male & group1 & group2 & group3 & group4 & group5 & group6 & group7 & group8 & sum group \\
\hline S & 0 & 9 & 0 & 10 & 9 & 0 & 0 & 10 & 38 \\
e & 0 & 5 & 0 & 4 & 3 & 0 & 0 & 18 \\
b & 0 & 0 & 0 & 2 & 2 & 0 & 0 & 1 \\
W & 0 & 2 & 0 & 0 & 2 & 0 & 0 & 4 & 8 \\
t & 0 & 0 & 0 & 0 & 1 & 0 & 0 & 0 & 1 \\
sum & 0 & 16 & 0 & 16 & 17 & 0 & 0 & 21 & 70 \\
\hline
\end{tabular}

Table5. Percentage of male.

\begin{tabular}{llllllllll}
\hline m & group1 & group2 & group3 & group4 & group5 & group6 & group7 & group8 & sum group \\
\hline s & 0 & 56.25 & 0 & 62.5 & 52.94117647 & 0 & 0 & 47.61904762 & 54.28571429 \\
e & 0 & 31.25 & 0 & 25 & 17.64705882 & 0 & 0 & 28.57142857 & 25.71428571 \\
b & 0 & 0 & 0 & 12.5 & 11.76470588 & 0 & 0 & 4.761904762 & 7.142857143 \\
w & 0 & 12.5 & 0 & 0 & 11.76470588 & 0 & 0 & 19.04761905 & 11.42857143 \\
t & 0 & 0 & 0 & 0 & 5.882352941 & 0 & 0 & 0 & 1.428571429 \\
sum & 0 & 100 & 0 & 100 & 100 & 0 & 0 & 100 & 100 \\
\hline
\end{tabular}

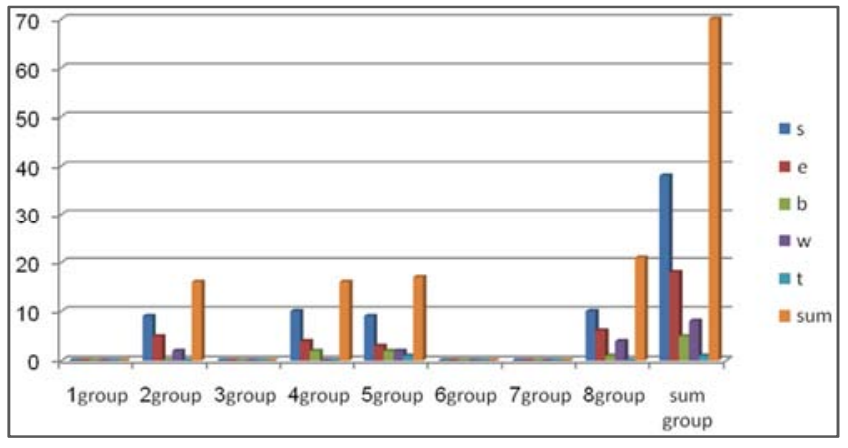

Figure 3. Percentage of male based on Interview.

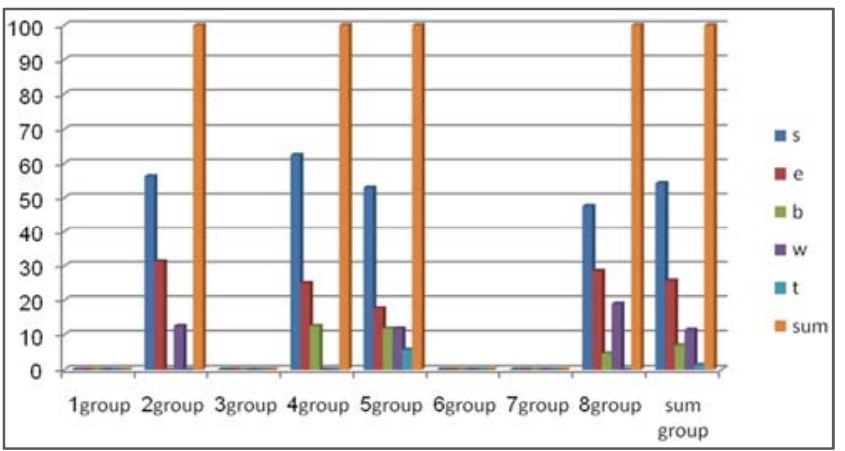

Figure 4. Percentage of male based on Interview.

Table 6. Sum of male \& female Interview.

\begin{tabular}{|c|c|c|c|c|c|c|c|c|c|}
\hline & group1 & group2 & group3 & group4 & group5 & group6 & group7 & group8 & sum group \\
\hline $\mathrm{s}$ & 13 & 9 & 4 & 10 & 9 & 12 & 6 & 10 & 73 \\
\hline e & 2 & 5 & 0 & 4 & 3 & 2 & 5 & 6 & 27 \\
\hline $\mathrm{b}$ & 1 & 0 & 8 & 2 & 2 & 1 & 1 & 1 & 16 \\
\hline w & 0 & 2 & 1 & 0 & 2 & 0 & 5 & 4 & 14 \\
\hline $\mathrm{t}$ & 0 & 0 & 0 & 0 & 1 & 0 & 0 & 0 & 1 \\
\hline sum & 16 & 16 & 13 & 16 & 17 & 15 & 17 & 21 & 131 \\
\hline
\end{tabular}

Table7. Percentage of sum male \& female.

\begin{tabular}{llllllllll}
\hline & group1 & group2 & group3 & group4 & group5 & group6 & group7 & group8 & sum group \\
\hline s & 0 & 56.25 & 0 & 62.5 & 52.94117647 & 0 & 0 & 47.61904762 & 55.72519084 \\
e & 0 & 31.25 & 0 & 25 & 17.64705882 & 0 & 0 & 28.57142857 & 20.61068702 \\
b & 0 & 0 & 0 & 12.5 & 11.76470588 & 0 & 0 & 4.761904762 & 12.21374046 \\
W & 0 & 12.5 & 0 & 0 & 11.76470588 & 0 & 0 & 19.04761905 & 10.6870229 \\
t & 0 & 0 & 0 & 0 & 5.882352941 & 0 & 0 & 0 & 0.763358779 \\
sum & 0 & 100 & 0 & 100 & 100 & 0 & 0 & 100 & 100 \\
\hline
\end{tabular}

Looking more carefully at table 2 indicates that though a strong tendency was found toward the use of present tense to talk about future, the subjects didn't perform so much like each other. For example the subjects number 1 and 6 use the present tense $81 \%$ and $80 \%$ respectively. However the subjects' number 3 and 7 used the present tense $31 \%$ and $38 \%$ respectively. Searching for the use of future tense, we noticed that 3 of our subjects (number 1, 4 and 6) did not use the future verb at all. Among the whole 131 sentences that we extracted, only 13 sentences possessed future verb (10\%) and $73 \%$ of sentences had present verb $(56 \%)$. In the whole 8 interviews we came across only 1 case of application of present perfect for talking about future.

Now let's investigate the issue from another point of view. Dows the age of people have any effect on their choice of future variability? Do the old people have a special tendency toward structure and the young people for the other ones? Table 3 shows the variations of future structures from the point of view of age. 


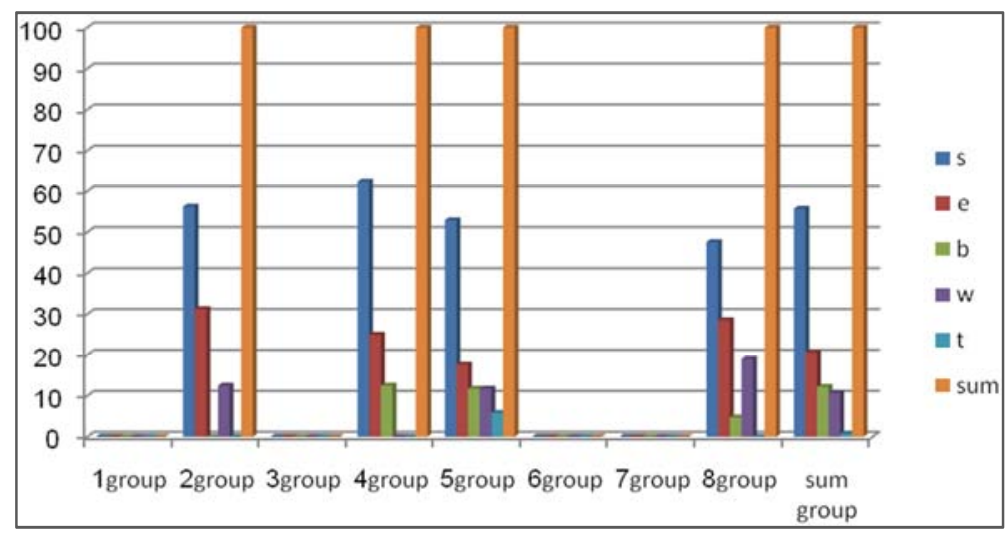

Figure 5. Percentage of sum male \& female Interview.

Table 8. Future variation with age Young.

\begin{tabular}{llllllllll}
\hline Young & group1 & group2 & group3 & group4 & group5 & group6 & group7 & group8 & sum group \\
\hline S & 13 & 0 & 4 & 10 & 9 & 0 & 0 & 0 & 36 \\
E & 2 & 0 & 0 & 4 & 3 & 0 & 0 & 0 & 0 \\
B & 1 & 0 & 8 & 2 & 2 & 0 & 0 & 0 \\
W & 0 & 0 & 1 & 0 & 2 & 0 & 0 & 0 & 3 \\
T & 0 & 0 & 0 & 0 & 1 & 0 & 0 & 0 & 13 \\
Sum & 16 & 0 & 13 & 16 & 17 & 0 & 0 & 0 & 62 \\
\hline
\end{tabular}

Table 9 Percentage of future variation with age.

\begin{tabular}{llllllllll}
\hline Young & group1 & group2 & group3 & group4 & group5 & group6 & group7 & group8 & sum group \\
\hline S & 81.25 & 0 & 30.77 & 62.5 & 52.94117647 & 0 & 0 & 0 & 58.06451613 \\
E & 12.5 & 0 & 0 & 25 & 17.64705882 & 0 & 0 & 0 & 14.51612903 \\
B & 6.25 & 0 & 61.54 & 12.5 & 11.76470588 & 0 & 0 & 0 & 20.96774194 \\
W & 0 & 0 & 7.692 & 0 & 11.76470588 & 0 & 0 & 0 & 4.838709677 \\
T & 0 & 0 & 0 & 0 & 5.882352941 & 0 & 0 & 0 & 1.612903226 \\
Sum & 100 & 0 & 100 & 100 & 100 & 0 & 0 & 0 & 100 \\
\hline
\end{tabular}

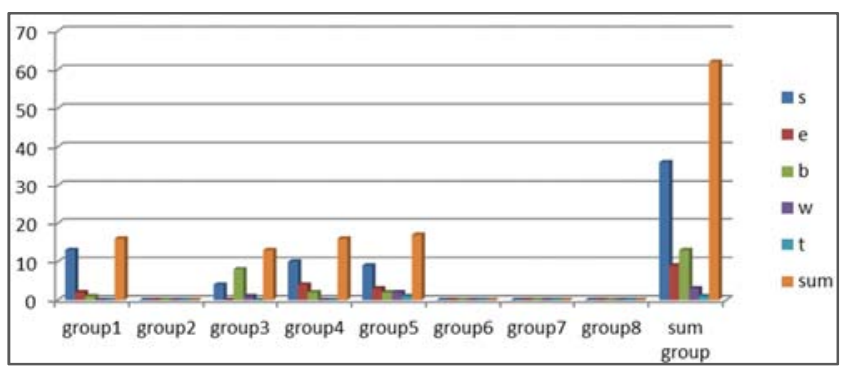

Figure 6. Percentage of future variation with age.

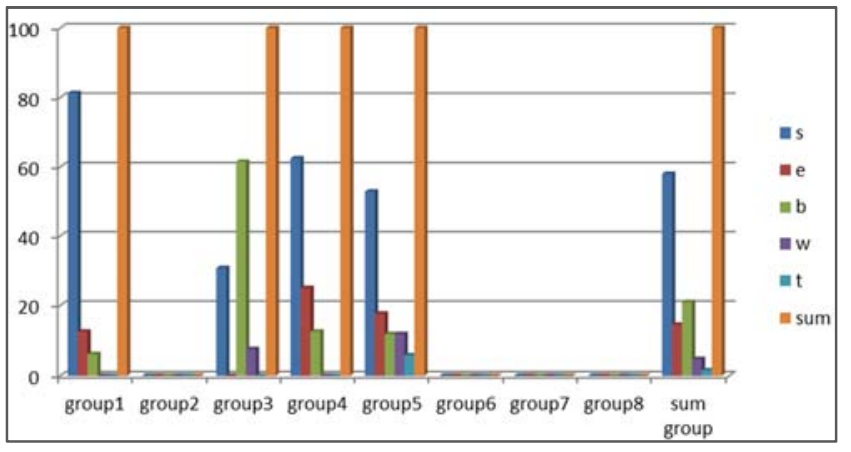

Figure 7. Percentage of future variation with age.

Table 10. Future variation with old age.

\begin{tabular}{llllllllll}
\hline old & group1 & group2 & group3 & group4 & group5 & group6 & group7 & group8 & sum group \\
\hline s & 0 & 5 & 0 & 0 & 0 & 12 & 6 & 10 & 33 \\
e & 0 & 5 & 0 & 0 & 0 & 2 & 5 & 6 & 18 \\
b & 0 & 0 & 0 & 0 & 0 & 1 & 1 & 1 & 3 \\
W & 0 & 2 & 0 & 0 & 0 & 0 & 5 & 4 & 11 \\
t & 0 & 0 & 0 & 0 & 0 & 0 & 0 & 0 & 0 \\
sum & 0 & 12 & 0 & 0 & 0 & 15 & 17 & 21 & 65 \\
\hline
\end{tabular}

Table 11. percentage of future variation with age.

\begin{tabular}{llllllllll}
\hline old & group1 & group2 & group3 & group4 & group5 & group6 & group7 & group8 & sum group \\
\hline $\mathrm{s}$ & 0 & 41.67 & 0 & 0 & 0 & 80 & 35.29 & 47.61904762 & 50.76923077 \\
$\mathrm{e}$ & 0 & 41.67 & 0 & 0 & 0 & 13.33 & 29.41 & 28.57142857 & 27.69230769 \\
\hline
\end{tabular}




\begin{tabular}{llllllllll}
\hline old & group1 & group2 & group3 & group4 & group5 & group6 & group7 & group8 & sum group \\
\hline b & 0 & 0 & 0 & 0 & 0 & 6.667 & 5.882 & 4.761904762 & 4.615384615 \\
W & 0 & 16.67 & 0 & 0 & 0 & 0 & 29.41 & 19.04761905 & 16.92307692 \\
t & 0 & 0 & 0 & 0 & 0 & 0 & 0 & 0 & 0 \\
sum & 0 & 100 & 0 & 0 & 0 & 100 & 100 & 100 & 100 \\
\hline
\end{tabular}

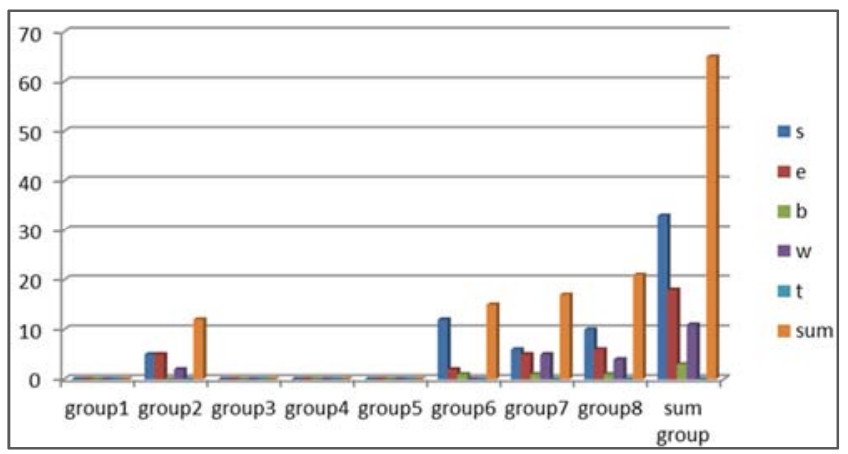

Figure 8. Percentage of future variation with age.

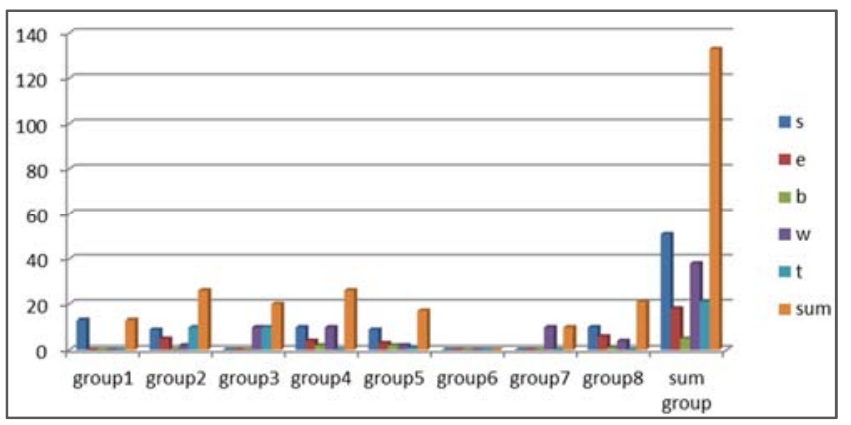

Figure 9. Percentage of sum future variation with age.

Table 12. sum future variation with age.

\begin{tabular}{llllllllll}
\hline sum & group1 & group2 & group3 & group4 & group5 & group6 & group7 & group8 & sum group \\
\hline $\mathrm{s}$ & 13 & 9 & 0 & 10 & 9 & 0 & 0 & 10 & 51 \\
$\mathrm{e}$ & 0 & 5 & 0 & 4 & 3 & 0 & 0 & 6 & 18 \\
$\mathrm{~b}$ & 0 & 0 & 0 & 2 & 2 & 0 & 0 & 1 & 5 \\
$\mathrm{w}$ & 0 & 2 & 10 & 10 & 2 & 0 & 10 & 4 & 38 \\
$\mathrm{t}$ & 0 & 10 & 10 & 0 & 1 & 0 & 0 & 0 & 21 \\
sum & 13 & 26 & 20 & 26 & 17 & 0 & 10 & 21 & 133 \\
\hline
\end{tabular}

Table 13. percentage of sum future variation with age.

\begin{tabular}{llllllllll}
\hline sum & group1 & group2 & group3 & group4 & group5 & group6 & group7 & group8 & sum group \\
\hline s & 0 & 34.62 & 0 & 38.46 & 52.94117647 & 0 & 0 & 47.61904762 & 38.34586466 \\
e & 0 & 19.23 & 0 & 15.38 & 17.64705882 & 0 & 0 & 28.57142857 & 13.53383459 \\
b & 0 & 0 & 0 & 7.692 & 11.76470588 & 0 & 0 & 4.761904762 & 3.759398496 \\
w & 0 & 7.692 & 0 & 38.46 & 11.76470588 & 0 & 0 & 19.04761905 & 28.57142857 \\
t & 0 & 38.46 & 0 & 0 & 5.882352941 & 0 & 0 & 0 & 15.78947368 \\
sum & 0 & 100 & 0 & 100 & 100 & 0 & 0 & 100 & 100 \\
\hline
\end{tabular}

A significant difference between these two groups was not found, but some points are worth considering. Both groups tend to use present verb more than other alternatives. The young group used 36 sentences in present $(58 \%)$ and the old group 37 sentences (54\%). But old people tend to use words like "bayad" and "shayad" more than young people $(\mathrm{e}=18)$. In the case of future verb which is somehow the main focus of our study, it is shown that although the overall percentage is not high $(16 \%)$, the old people used the future verb more than young group $(\mathrm{w}=15 \%$ for old group and $\mathrm{w}=5 \%$ for the young group).

The next factor that we are going to consider with the future variation is the animacy of subject. It is felt that animate or inanimate subject of sentences influences the selection of the mood of the future tense. Table 4 shows these variations.

Those sentences which had inanimate subjects tend more to use future verb rather than sentences with animate subjects $(\mathrm{w}=7 \%$ for sentences with animate subjects and $\mathrm{w}=17 \%$ for sentences with inanimate subject).

Table 14. Future variation with animacy of subject Animate.

\begin{tabular}{|c|c|c|c|c|c|c|c|c|c|}
\hline aimate & group1 & group2 & group3 & group4 & group5 & group6 & group7 & group8 & sum group \\
\hline $\mathrm{s}$ & 11 & 7 & 0 & 3 & 7 & 9 & 5 & 5 & 47 \\
\hline $\mathrm{e}$ & 2 & 3 & 0 & 3 & 2 & 2 & 4 & 4 & 20 \\
\hline b & 1 & 0 & 8 & 1 & 2 & 1 & 1 & 1 & 15 \\
\hline w & 0 & 2 & 0 & 0 & 1 & 0 & 1 & 2 & 6 \\
\hline $\mathrm{t}$ & 0 & 0 & 0 & 0 & 0 & 0 & 0 & 0 & 0 \\
\hline sum & 14 & 12 & 8 & 7 & 12 & 12 & 11 & 12 & 88 \\
\hline
\end{tabular}


Table 15. Percentage of future variation with animacy of subject.

\begin{tabular}{|c|c|c|c|c|c|c|c|c|c|}
\hline aimate & group1 & group2 & group3 & group4 & group5 & group6 & group7 & group8 & sum group \\
\hline $\mathrm{s}$ & 78.57 & 58.33 & 0 & 42.86 & 58.33333333 & 75 & 45.45454545 & 41.66666667 & 53.40909091 \\
\hline e & 14.29 & 25 & 0 & 42.86 & 16.66666667 & 16.66666667 & 36.36363636 & 33.33333333 & 22.72727273 \\
\hline b & 7.143 & 0 & 100 & 14.29 & 16.66666667 & 8.333333333 & 9.090909091 & 8.333333333 & 17.04545455 \\
\hline W & 0 & 16.67 & 0 & 0 & 8.333333333 & 0 & 9.090909091 & 16.66666667 & 6.818181818 \\
\hline $\mathrm{t}$ & 0 & 0 & 0 & 0 & 0 & 0 & 0 & 0 & 0 \\
\hline sum & 100 & 100 & 100 & 100 & 100 & 100 & 100 & 100 & 100 \\
\hline
\end{tabular}
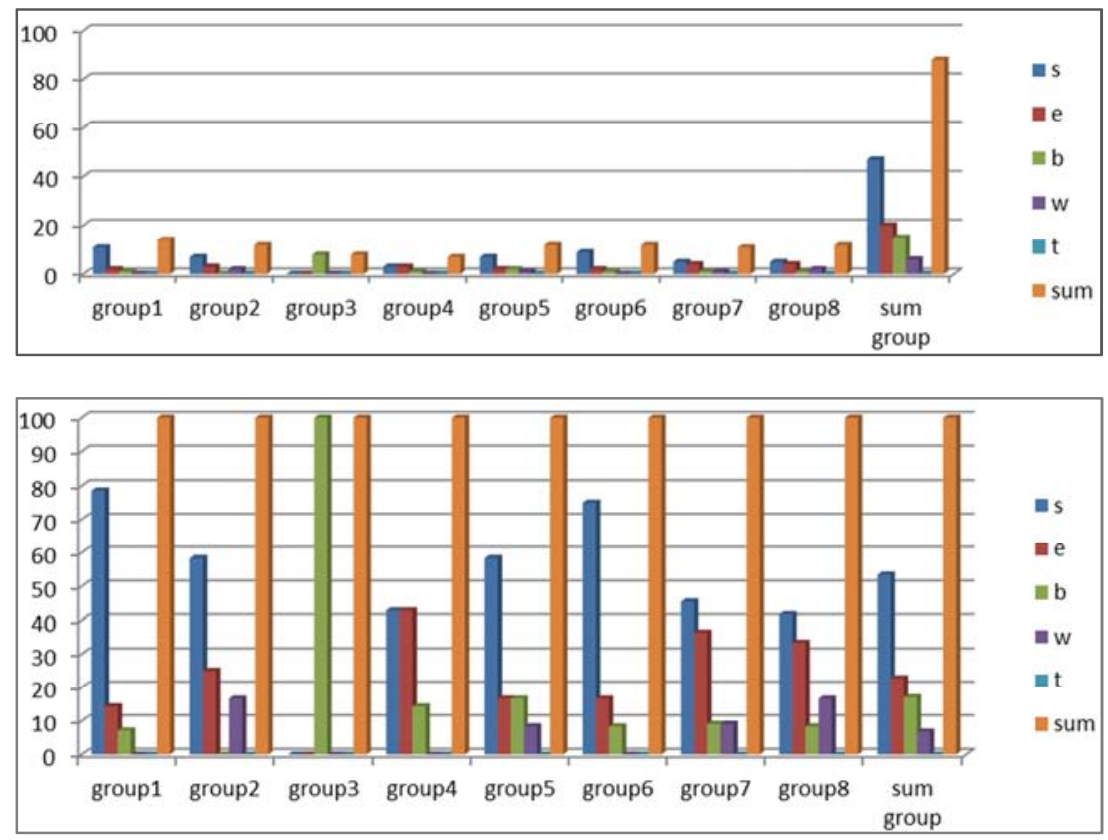

Figure 10. Percentage of future variation with animacy of subject.

Table 16. Inanimate: future variation with animacy of subject.

\begin{tabular}{|c|c|c|c|c|c|c|c|c|c|}
\hline Inanimate & group1 & group2 & group3 & group4 & group5 & group6 & group7 & group8 & sum group \\
\hline s & 2 & 2 & 4 & 7 & 2 & 3 & 1 & 5 & 26 \\
\hline $\mathrm{e}$ & 0 & 2 & 0 & 1 & 1 & 0 & 1 & 2 & 7 \\
\hline b & 0 & 0 & 0 & 1 & 0 & 0 & 0 & 0 & 1 \\
\hline w & 0 & 0 & 1 & 0 & 1 & 0 & 3 & 2 & 7 \\
\hline $\mathrm{t}$ & 0 & 0 & 0 & 0 & 1 & 0 & 0 & 0 & 1 \\
\hline sum & 2 & 4 & 5 & 9 & 5 & 3 & 5 & 9 & 42 \\
\hline
\end{tabular}

Table 17. Percentage of future variation with animacy of subject.

\begin{tabular}{|c|c|c|c|c|c|c|c|c|c|}
\hline Inanimate & group1 & group2 & group3 & group4 & group5 & group6 & group7 & group8 & sum group \\
\hline $\mathrm{s}$ & 100 & 50 & 80 & 77.78 & 40 & 100 & 20 & 55.55555556 & 61.9047619 \\
\hline e & 0 & 50 & 0 & 11.11 & 20 & 0 & 20 & 22.22222222 & 16.66666667 \\
\hline $\mathrm{b}$ & 0 & 0 & 0 & 11.11 & 0 & 0 & 0 & 0 & 2.380952381 \\
\hline w & 0 & 0 & 20 & 0 & 20 & 0 & 60 & 22.22222222 & 16.66666667 \\
\hline $\mathrm{t}$ & 0 & 0 & 0 & 0 & 20 & 0 & 0 & 0 & 2.380952381 \\
\hline sum & 100 & 100 & 100 & 100 & 100 & 100 & 100 & 100 & 100 \\
\hline
\end{tabular}

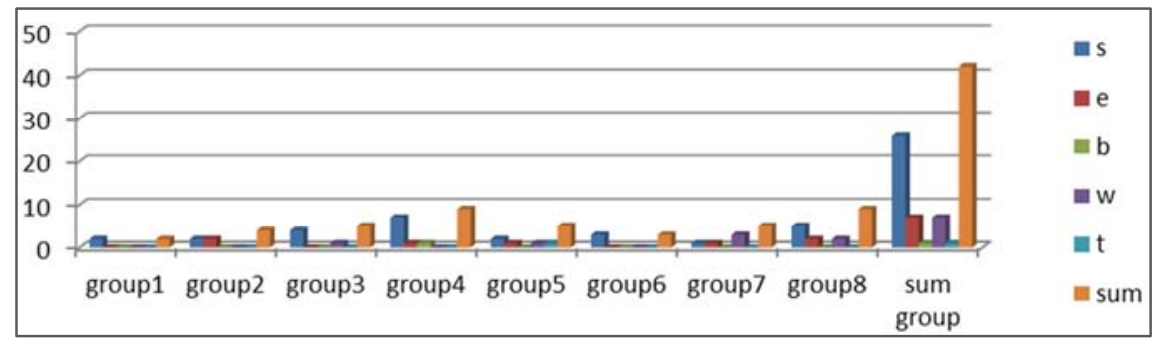




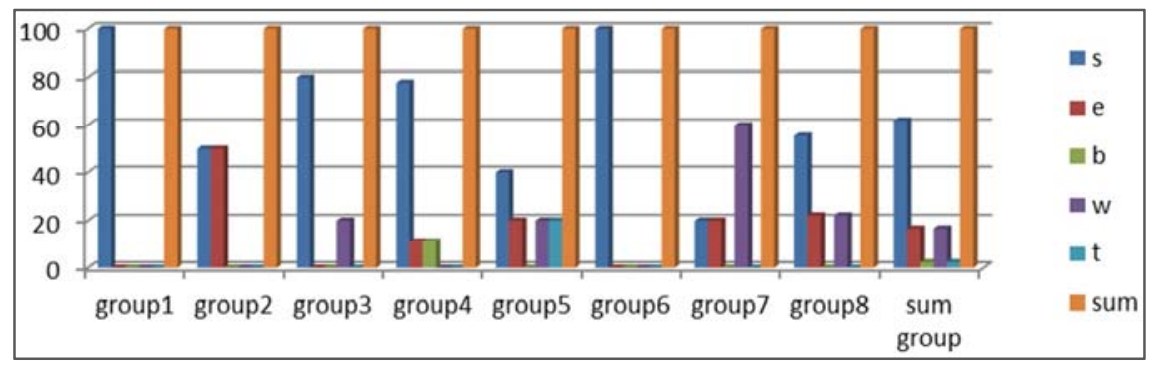

Figure 11. Percentage of future variation with animacy of subject.

Table 18. Sum: future variation with animacy of subject

\begin{tabular}{llllllllll}
\hline sum & group1 & group2 & group3 & group4 & group5 & group6 & group7 & group8 & sum group \\
\hline s & 13 & 9 & 4 & 10 & 9 & 12 & 6 & 10 & 73 \\
e & $\mathbf{2}$ & $\mathbf{5}$ & $\mathbf{0}$ & $\mathbf{4}$ & $\mathbf{3}$ & $\mathbf{2}$ & $\mathbf{5}$ & $\mathbf{6}$ & $\mathbf{2}$ \\
$\mathrm{b}$ & 1 & 0 & 8 & 2 & 2 & 1 & 1 & 1 & 16 \\
w & 0 & 2 & 1 & 0 & 2 & 0 & 4 & 4 & 13 \\
t & 0 & 0 & 0 & 0 & 1 & 0 & 0 & 0 & 1 \\
sum & 16 & 16 & 13 & 16 & 17 & 15 & 16 & 21 & 130 \\
\hline
\end{tabular}

Table 19. Percentage of future variation with animacy of subject.

\begin{tabular}{llllllllll}
\hline sum & group1 & group2 & group3 & group4 & group5 & group6 & group7 & group8 & sum group \\
\hline $\mathrm{s}$ & 81.25 & 56.25 & 30.77 & 62.5 & 52.94117647 & 80 & 37.5 & 47.61904762 & 56.15384615 \\
$\mathrm{e}$ & 12.5 & 31.25 & 0 & 25 & 17.64705882 & 13.33 & 31.25 & 28.57142857 & 20.76923077 \\
$\mathrm{~b}$ & 6.25 & 0 & 61.54 & 12.5 & 11.76470588 & 6.667 & 6.25 & 4.761904762 & 12.30769231 \\
$\mathrm{~W}$ & 0 & 12.5 & 7.692 & 0 & 11.76470588 & 0 & 25 & 19.04761905 & 10 \\
$\mathrm{t}$ & 0 & 0 & 0 & 0 & 5.882352941 & 0 & 0 & 0 & 0.769230769 \\
sum & 100 & 100 & 100 & 100 & 100 & 100 & 100 & 100 & 100 \\
\hline
\end{tabular}
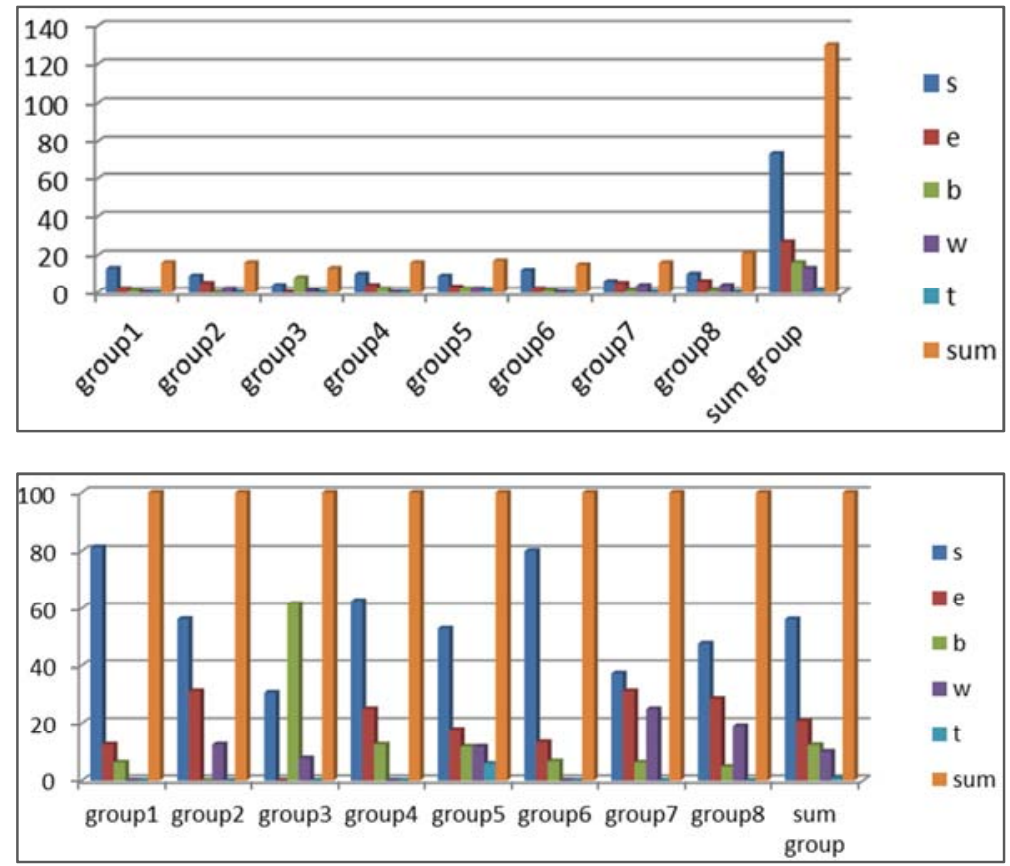

Figure 12. Percentage of future variation with animacy of subject.

We felt that interviewers may affect the subject's choice of words and tenses. One interview may conduct the interview in a very naturalistic and informal manner; the other one may not be skillful enough and direct the interview very formally. Therefore we took the interviewers as a factor group (codes "c" and "d"). Table 5 shows the interviews which are arranged by the interviewers. The first five subjects were interviewed by the first interviewer and the last three ones with the second interviewer.

Investigating and scrutinizing table $5 \mathrm{~T}$ we come to this 
conclusion that the interviewers did not have very significant role in the results of the study. The percentage of each variation for the two interviewers are not so different. But we see that the second interviewers has elicited more future verb rather than the first interviewer. $(\mathrm{w}=6 \%$ for the first interviewer and $\mathrm{w}=15 \%$ for the second interviewer). Among the whole 78 sentences which are extracted from the interviews of the first interviewer just five sentences possessed future verb and in the case of the second interviewer, the whole number of sentences extracted is 52 and 8 sentences had future verb. These differences may also be accounted for by other factors of subjects which are not simply attributable to interviewers.

Table 20. Future variation with interviewers.

\begin{tabular}{|c|c|c|c|c|c|c|c|c|c|}
\hline first interviewer & group1 & group2 & group3 & group4 & group5 & group6 & group7 & group8 & sum group \\
\hline $\mathrm{s}$ & 13 & 9 & 4 & 10 & 9 & 0 & 0 & 0 & 45 \\
\hline $\mathrm{e}$ & 2 & 5 & 0 & 4 & 3 & 0 & 0 & 0 & 14 \\
\hline b & 1 & 0 & 8 & 2 & 2 & 0 & 0 & 0 & 13 \\
\hline $\mathrm{t}$ & 0 & 0 & 0 & 0 & 1 & 0 & 0 & 0 & 1 \\
\hline sum & 16 & 16 & 13 & 16 & 17 & 0 & 0 & 0 & 78 \\
\hline
\end{tabular}

Table 21. Percentage of future variation with interviewers.

\begin{tabular}{|c|c|c|c|c|c|c|c|c|c|}
\hline sum first interviewer & group1 & group2 & group3 & group4 & group5 & group6 & group7 & group8 & sum group \\
\hline $\mathrm{s}$ & 81.25 & 56.25 & 30.77 & 62.5 & 52.94117647 & 0 & 0 & \#DIV/0! & 57.69230769 \\
\hline e & 12.5 & 31.25 & 0 & 25 & 17.64705882 & 0 & 0 & \#DIV/0! & 17.94871795 \\
\hline $\mathrm{b}$ & 6.25 & 0 & 61.54 & 12.5 & 11.76470588 & 0 & 0 & \#DIV/0! & 16.66666667 \\
\hline w & 0 & 12.5 & 7.692 & 0 & 11.76470588 & 0 & 0 & \#DIV/0! & 6.41025641 \\
\hline $\mathrm{t}$ & 0 & 0 & 0 & 0 & 5.882352941 & 0 & 0 & \#DIV/0! & 1.282051282 \\
\hline sum & 100 & 100 & 100 & 100 & 100 & 0 & 0 & \#DIV/0! & 100 \\
\hline
\end{tabular}
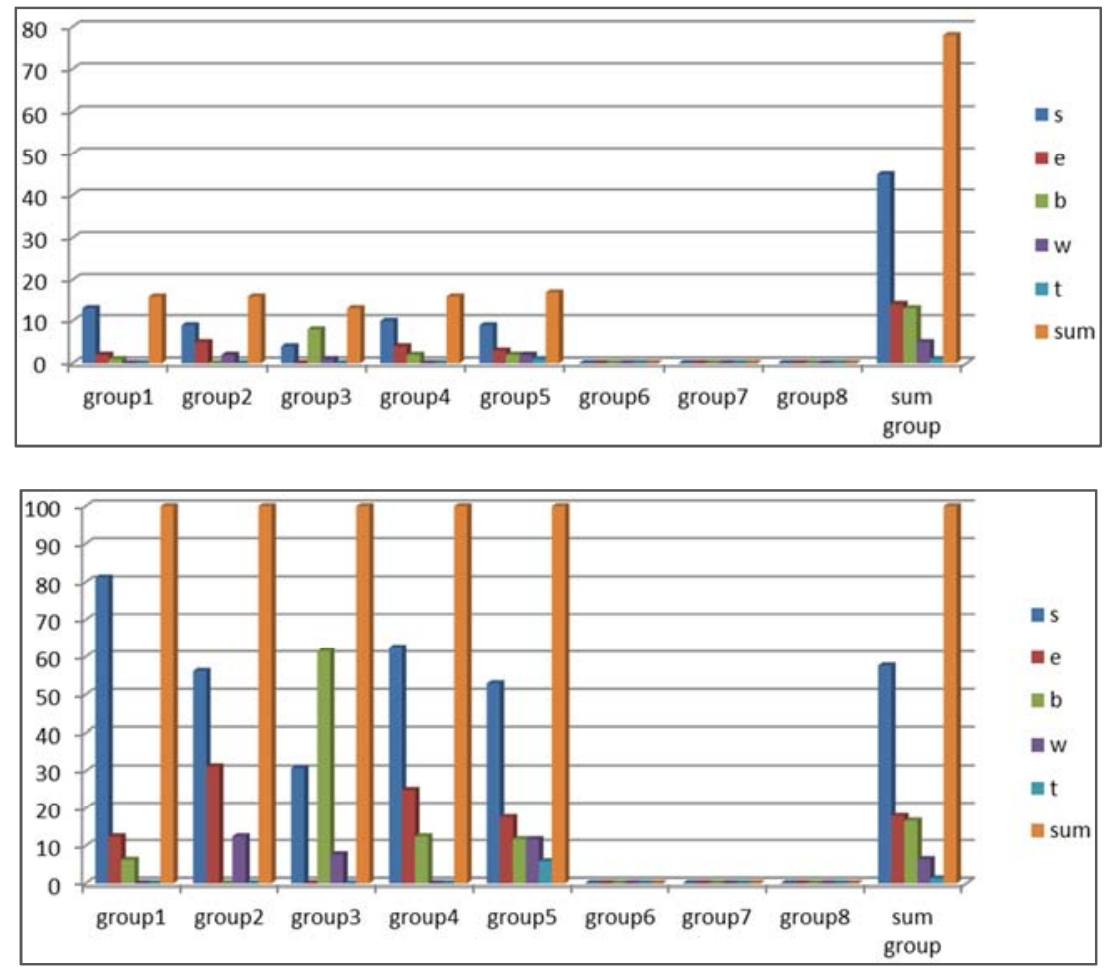

Figure 13. Percentage of future variation with interviewers.

Table 21. Second: future variation with interviewers.

\begin{tabular}{|c|c|c|c|c|c|c|c|c|c|}
\hline second interviewer & group1 & group2 & group3 & group4 & group5 & group6 & group7 & group8 & sum group \\
\hline $\mathrm{s}$ & 0 & 0 & 0 & 0 & 0 & 12 & 6 & 10 & 28 \\
\hline $\mathrm{e}$ & 0 & 0 & 0 & 0 & 0 & 2 & 5 & 6 & 13 \\
\hline $\mathrm{b}$ & 0 & 0 & 0 & 0 & 0 & 1 & 1 & 1 & 3 \\
\hline w & 0 & 0 & 0 & 0 & 0 & 0 & 4 & 4 & 8 \\
\hline $\mathrm{t}$ & 0 & 0 & 0 & 0 & 0 & 0 & 0 & 0 & 0 \\
\hline sum & 0 & 0 & 0 & 0 & 0 & 15 & 16 & 21 & 52 \\
\hline
\end{tabular}


Table 22. Percentage of future variation with interviewers.

\begin{tabular}{|c|c|c|c|c|c|c|c|c|c|}
\hline second interviewer & group1 & group2 & group3 & group4 & group5 & group6 & group7 & group8 & sum group \\
\hline $\mathrm{s}$ & 0 & 0 & 0 & 0 & 0 & 80 & 37.5 & 47.61904762 & 53.84615385 \\
\hline $\mathrm{e}$ & 0 & 0 & 0 & 0 & 0 & 13.33 & 31.25 & 28.57142857 & 25 \\
\hline $\mathrm{b}$ & 0 & 0 & 0 & 0 & 0 & 6.667 & 6.25 & 4.761904762 & 5.769230769 \\
\hline $\mathrm{w}$ & 0 & 0 & 0 & 0 & 0 & 0 & 25 & 19.04761905 & 15.38461538 \\
\hline $\mathrm{t}$ & 0 & 0 & 0 & 0 & 0 & 0 & 0 & 0 & 0 \\
\hline sum & 0 & 0 & 0 & 0 & 0 & 100 & 100 & 100 & 100 \\
\hline
\end{tabular}
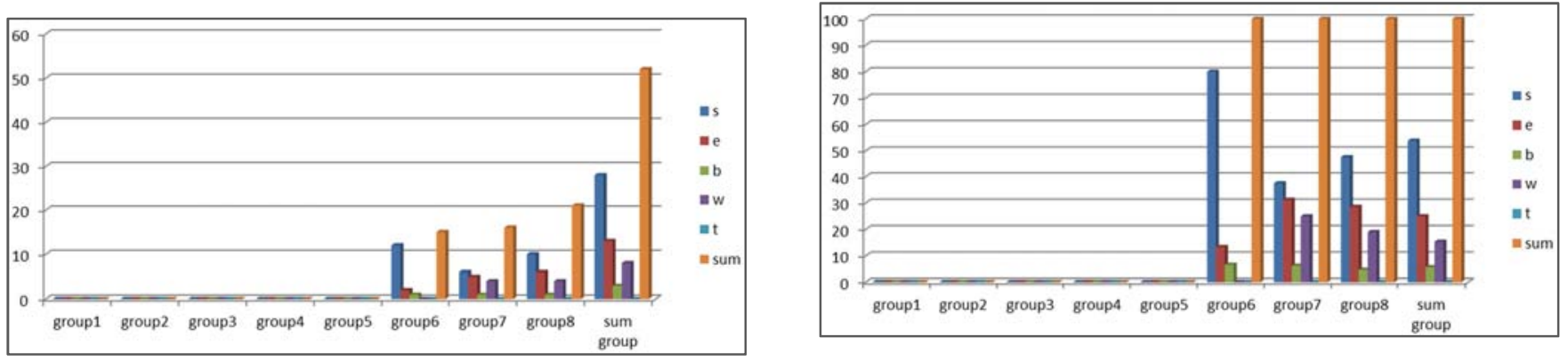

Figure 14. Percentage of future variation with interviewers.

Table 23. Sum: future variation with interviewers.

\begin{tabular}{|c|c|c|c|c|c|c|c|c|c|}
\hline sum & group1 & group2 & group3 & group4 & group5 & group6 & group7 & group8 & sum group \\
\hline $\mathrm{s}$ & 13 & 9 & 4 & 10 & 9 & 12 & 6 & 10 & 73 \\
\hline $\mathrm{e}$ & 2 & 5 & 0 & 4 & 3 & 2 & 5 & 6 & 27 \\
\hline w & 0 & 2 & 1 & 0 & 2 & 0 & 4 & 4 & 13 \\
\hline $\mathrm{t}$ & 0 & 0 & 0 & 0 & 1 & 0 & 0 & 0 & 1 \\
\hline sum & 16 & 16 & 13 & 16 & 17 & 15 & 16 & 21 & 130 \\
\hline
\end{tabular}

Table 24. Percentage of future variation with interviewers.

\begin{tabular}{|c|c|c|c|c|c|c|c|c|c|}
\hline sum & group1 & group2 & group3 & group4 & group5 & group6 & group7 & group8 & sum group \\
\hline $\mathrm{s}$ & 81.25 & 56.25 & 30.77 & 62.5 & 52.94117647 & 80 & 37.5 & 47.61904762 & 56.15384615 \\
\hline $\mathrm{e}$ & 12.5 & 31.25 & 0 & 25 & 17.64705882 & 13.33 & 31.25 & 28.57142857 & 20.76923077 \\
\hline w & 0 & 12.5 & 7.692 & 0 & 11.76470588 & 0 & 25 & 19.04761905 & 10 \\
\hline $\mathrm{t}$ & 0 & 0 & 0 & 0 & 5.882352941 & 0 & 0 & 0 & 0.769230769 \\
\hline sum & 100 & 100 & 100 & 100 & 100 & 100 & 100 & 100 & 100 \\
\hline
\end{tabular}

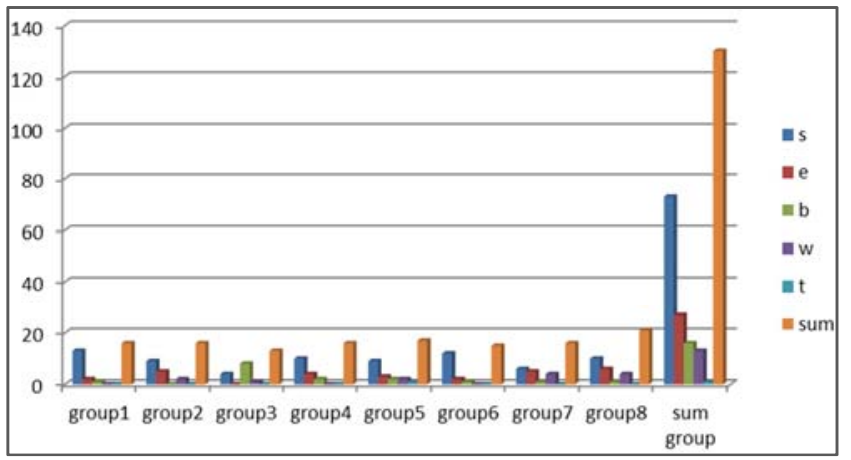

Figure 15. Percentage of future variation with interviewers.

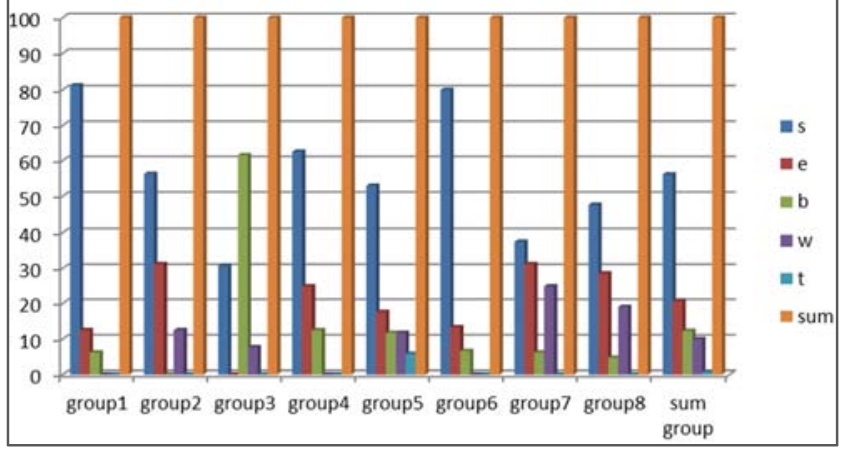

Figure 16. Percentage of future variation with interviewers. 
The last factor that we are going to investigate along with future variability is the absence or presence of temporal adverbials in the sentences used ( + shows the presence of adverb and - show the absence of that). Table 6 summarized the data gathered from our subjects based on this factor. The significant difference that stands our regarding the absence or presence of adverb of is that among the sentences which lack the adverb, none of them are made with words like "bayad" and "shayad" $(b=0)$. But the same case for the sentences with temporal adverbial is 16 sentences $(b=14 \%)$. Among the 130 sentences which are extracted only 16 sentences had temporal adverbial. The use of future verb is not so different $(\mathrm{w}=12 \%$ for sentences with adverbs and $\mathrm{w}=10 \%$ for sentences without adverb).

Table 25. Future Variation with absence or presence of temporal adverb.

\begin{tabular}{|c|c|c|c|c|c|c|c|c|c|}
\hline absence & group1 & group2 & group3 & group4 & group5 & group6 & group7 & group8 & sum group \\
\hline $\mathrm{s}$ & 9 & 8 & 4 & 8 & 7 & 12 & 4 & 10 & 62 \\
\hline $\mathrm{e}$ & 2 & 3 & 0 & 4 & 3 & 2 & 4 & 6 & 24 \\
\hline b & 1 & 0 & 8 & 2 & 2 & 1 & 1 & 1 & 16 \\
\hline w & 0 & 2 & 1 & 0 & 2 & 0 & 4 & 2 & 11 \\
\hline $\mathrm{t}$ & 0 & 0 & 0 & 0 & 1 & 0 & 0 & 0 & 1 \\
\hline sum & 12 & 13 & 13 & 14 & 15 & 15 & 13 & 19 & 114 \\
\hline
\end{tabular}

Table 26. Percentage of Future variation with absence or presence of temporal adverb.

\begin{tabular}{llllllllll}
\hline absence & group1 & group2 & group3 & group4 & group5 & group6 & group7 & group8 & sum group \\
\hline S & 75 & 61.54 & 30.77 & 57.14 & 46.66666667 & 80 & 30.77 & 52.63157895 & 54.38596491 \\
e & 16.67 & 23.08 & 0 & 28.57 & 20 & 13.33 & 30.77 & 31.57894737 & 21.05263158 \\
b & 8.333 & 0 & 61.54 & 14.29 & 13.33333333 & 6.667 & 7.692 & 5.263157895 & 14.03508772 \\
W & 0 & 15.38 & 7.692 & 0 & 13.33333333 & 0 & 30.77 & 10.52631579 & 9.649122807 \\
t & 0 & 0 & 0 & 0 & 6.666666667 & 0 & 0 & 0 \\
sum & 100 & 100 & 100 & 100 & 100 & 100 & 100 & 100 & 100 \\
\hline
\end{tabular}

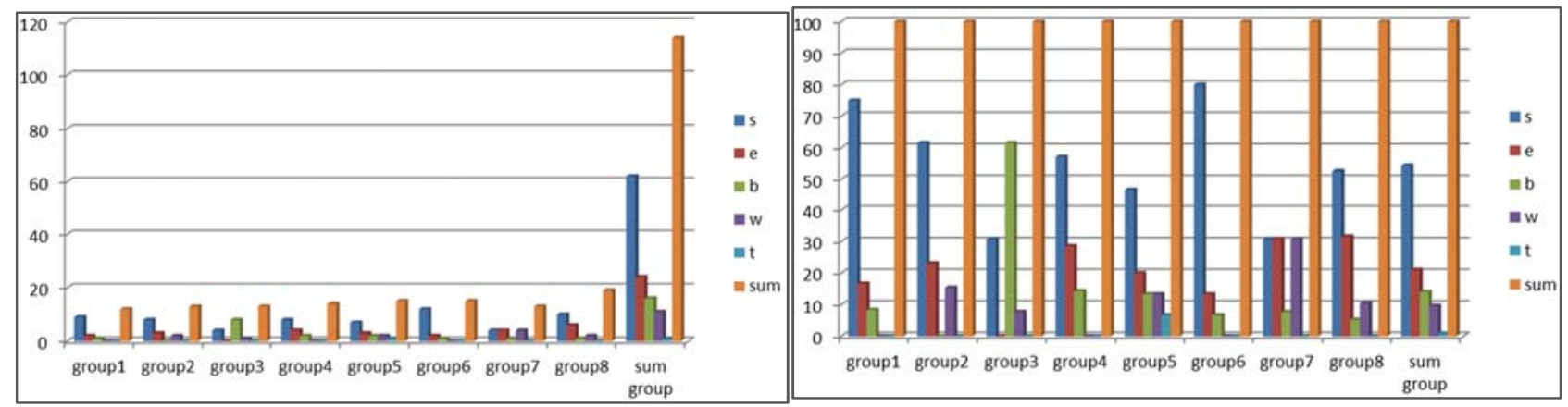

Figure 17. Percentage of Future variation with absence or presence of temporal adverb.

Table 27. Future variation with absence or presence of temporal adverb.

\begin{tabular}{|c|c|c|c|c|c|c|c|c|c|}
\hline presence & group1 & group2 & group3 & group4 & group5 & group6 & group7 & group8 & sum group \\
\hline $\mathrm{s}$ & 4 & 1 & 0 & 2 & 2 & 0 & 2 & 0 & 11 \\
\hline e & 0 & 2 & 0 & 0 & 0 & 0 & 1 & 0 & 3 \\
\hline $\mathrm{b}$ & 0 & 0 & 0 & 0 & 0 & 0 & 0 & 0 & 0 \\
\hline $\mathrm{w}$ & 0 & 0 & 0 & 0 & 0 & 0 & 0 & 0 & 0 \\
\hline $\mathrm{t}$ & 0 & 0 & 0 & 0 & 0 & 0 & 0 & 0 & 0 \\
\hline sum & 4 & 3 & 0 & 2 & 2 & 0 & 3 & 0 & 14 \\
\hline
\end{tabular}

Table 28. Percentage of Future variation with absence or presence of temporal adverb.

\begin{tabular}{|c|c|c|c|c|c|c|c|c|c|}
\hline presence & group1 & group2 & group3 & group4 & group5 & group6 & group7 & group8 & sum group \\
\hline $\mathrm{s}$ & 100 & 33.33 & 0 & 100 & 100 & 0 & 66.67 & 0 & 78.57142857 \\
\hline $\mathrm{e}$ & 0 & 66.67 & 0 & 0 & 0 & 0 & 33.33 & 0 & 21.42857143 \\
\hline $\mathrm{b}$ & 0 & 0 & 0 & 0 & 0 & 0 & 0 & 0 & 0 \\
\hline w & 0 & 0 & 0 & 0 & 0 & 0 & 0 & 0 & 0 \\
\hline $\mathrm{t}$ & 0 & 0 & 0 & 0 & 0 & 0 & 0 & 0 & 0 \\
\hline sum & 100 & 100 & 0 & 100 & 100 & 0 & 100 & 0 & 100 \\
\hline
\end{tabular}



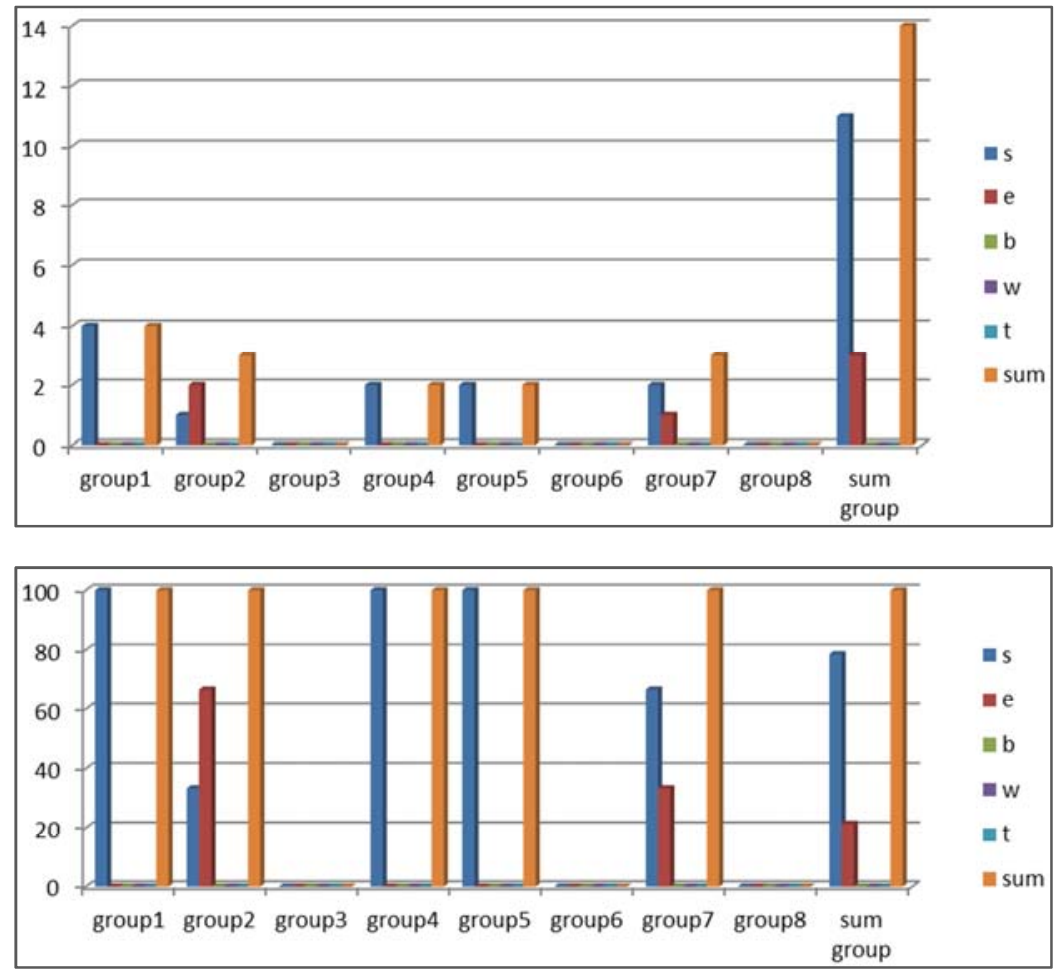

Figure 18. Future variation with absence or presence of temporal adverb.

Table 29. Future variation with absence or presence of temporal adverb.

\begin{tabular}{llllllllll}
\hline sum & group1 & group2 & group3 & group4 & group5 & group6 & group7 & group8 & sum group \\
\hline S & 13 & 9 & 4 & 10 & 9 & 12 & 6 & 10 & 73 \\
e & 2 & 5 & 0 & 4 & 3 & 2 & 5 & 6 & 27 \\
b & 1 & 0 & 8 & 2 & 2 & 1 & 1 & 1 & 16 \\
w & 0 & 2 & 1 & 0 & 2 & 0 & 4 & 4 & 13 \\
t & 0 & 0 & 0 & 0 & 1 & 0 & 0 & 0 & 1 \\
sum & 16 & 16 & 13 & 16 & 17 & 15 & 16 & 21 & 130 \\
\hline
\end{tabular}

Table 30. Percentage of Future variation with absence or presence of temporal adverb.

\begin{tabular}{lllllllll}
\hline sum & group1 & group2 & group3 & group4 & group5 & group6 & group7 & group8 \\
\hline $\mathrm{s}$ & 81.25 & 56.25 & 30.77 & 62.5 & 52.94117647 & 80 & 37.5 & 47.61904762 \\
$\mathrm{e}$ & 12.5 & 31.25 & 0 & 25 & 17.64705882 & 13.33 & 31.25 & 28.57142857 \\
$\mathrm{~b}$ & 6.25 & 0 & 61.54 & 12.5 & 11.76470588 & 6.667 & 6.25 & 4.761904762 \\
$\mathrm{~W}$ & 0 & 12.5 & 7.692 & 0 & 11.76470588 & 0 & 25 & 12.30769231 \\
$\mathrm{t}$ & 0 & 0 & 0 & 0 & 5.882352941 & 0 & 0 & 19.04761905 \\
sum & 100 & 100 & 100 & 100 & 100 & 100 & 100 & 0 \\
\hline
\end{tabular}

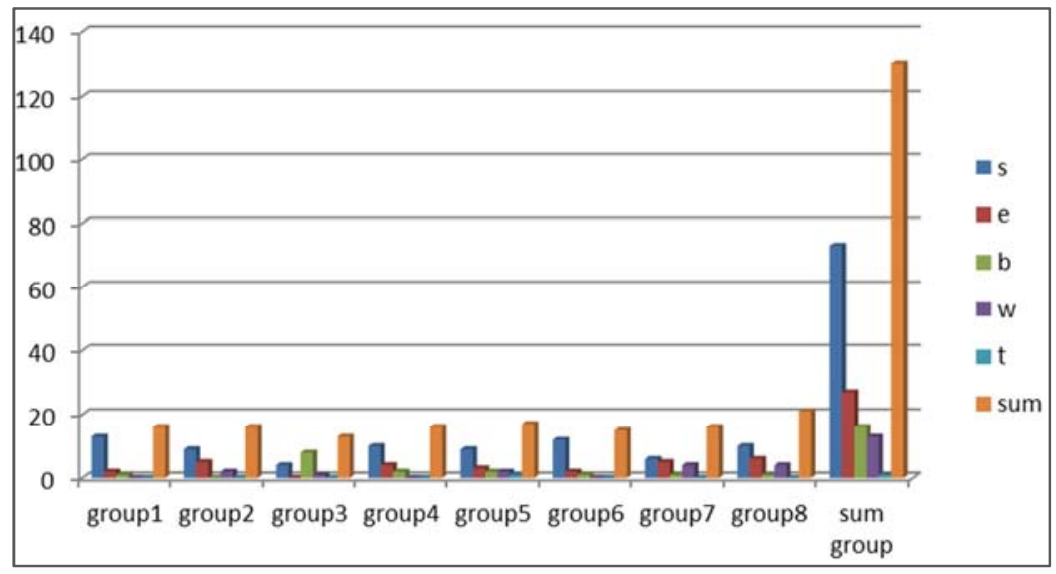




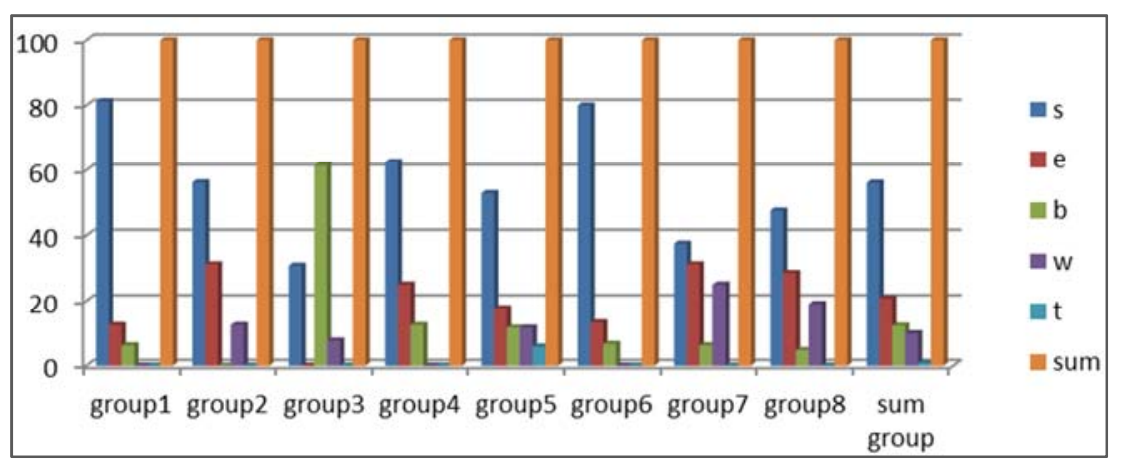

Figure 19. Percentage of Future variation with absence or presence of temporal adverb.

\section{Conclusion}

In conclusion we want to restate that future time is difficult to perceive and describe and for expressing a future activity and the notion of futurity we many choices at our disposal. In the case of Farsi or Persian we can conclude that although future verb has its own structure and definition, it is not applied most of the time in the speaking of Tehrani speakers of Farsi. Present tense is the variation which is proved to be used for the majority of cases to talk about future.

\section{References}

[1] Van der Geer, J., Hanraads, J. A. J., \& Lupton R. A. (2000). The art of writing a scientific article. Journal of Scientific Communications, 163, 51-59.

[2] Eichman, p, (2003). "observation on futurity".

[3] Freduenthal, D, (2001). "Simulating the temporal reference of Dutch and English".

[4] Lin, J, 2001. "Selectional restrictions of tenses and temporal reference of Chinese bare sentences". Lingua, 113, 271-302.

[5] Lotfi, A. H, (1997). "Tense, IP and parametric Variation". Proceeding of conference on Language, Cognition, and Interpretation.
[6] Lyons, C. G, (2002). "A look into the Spanish future". University college London, linguistic section and School of communication studies, N. Ireland Polytechnic, UK.

[7] Sarkar, A, (2000). "The conflict between future tense and modality: the case of will in English". Dep. Of computer and information science, university of Pennsylvania.

[8] Schwarze, C, (2001). "Do sentences have tenses?" The International LFG conference, Hong Kong, June 25-27.

[9] Scriven, M, 2001. "Evaluation: Future tense".

[10] Taghva, M., Beckly, R., \& Sadeh, M,(2003). "A stemming algorithm for the Farsi Language". Information Science Institute, University of Nevada, Las Vegas.

[11] Tomic, O. M, (2003). "The syntax of Balkan Slavic future tenses". Lingua, 114, 517-542.

[12] Walker, J. A; poplak, Sh., Cacoullos, P. T, (2004). "Looking into the future in English and French". Sociolinguistic Symposium 15, University of Newcastle- Upon- Tyne.

[13] Vincent, Diane and David Sankoff. 1992. Punctors: a pragmatic variable. Language Variation and Change, 4. 20616.

[14] Weiner, E. and William Labov. 1983Constraints on the agentless passive. Journal of Linguistics 19. 29-58.

[15] Xu, Y., \& Brown, G. T. L. (2016). Teacher assessment literacy in practice: A reconceptualization. Teaching and Teacher Education, 149-162. 